\title{
Timing of songbird migration: individual consistency within and between seasons
}

\author{
Kasper Thorup, Yannis Vardanis, Anders P. Tøttrup, Mikkel Willemoes Kristensen \\ and Thomas Alerstam
}

K. Thorup (kthorup@snm.ku.dk), A. P. Tottrup and M. Willemoes Kristensen, Center for Macroecology, Evolution and Climate, Natural History Museum of Denmark, Univ. of Copenhagen, Universitetsparken 15, DK-2100 Copenhagen, Denmark. - Y. Vardanis and T. Alerstam, Dept of Biology, Lund Univ., Ecology Building, SE-22362 Lund, Sweden.

\begin{abstract}
The timing of migration is generally considered of utmost importance for reproduction and survival, and timing is furthermore considered to be under strong genetic control. The individual timing of migration is presumably a result of a combination of genetic, phenotypic and environmental factors as well as some degree of randomness. However, potential differences in consistency of timing between spring and autumn and between migration strategies are not well studied. Using long-term Danish ringing data, we study such differences by correlating date of ringing with date of recaptures for a suite of common migrating passerines in Denmark. We found that individuals marked early in one year tended to be recaptured early in the same season in a following year indicating that individuals time their migration in spring or autumn similarly between years. The relationship between spring and autumn migration was overall slightly negative, suggesting that birds arriving early in spring tended to depart late in autumn and vice versa. There were only weak effects of geographical location on timing, suggesting that the patterns found are not primarily caused by different populations being involved. Knowledge of individual consistency in migration timing is needed for understanding changes in migration timing. The consistent patterns of repeatabilities within and between seasons found here highlight the importance of timing of migration in songbirds.
\end{abstract}

Recently, there has been increasing interest in phenology in migratory birds, and studies have documented changes in annual schedules, e.g. spring arrival (Lehikoinen et al. 2004, Gordo 2007) or date of egg laying (Bairlein and Winkel 2001, Dunn 2004). In general, the arrival of migratory birds in spring has advanced during the last few decades with longer-distance migrants being less affected than shorterdistance migrants (Hüppop and Hüppop 2003, Jenni and Kéry 2003, Tøttrup et al. 2006b, Thorup et al. 2007). The effects of climate change on autumn departures have been much less clear-cut (Bairlein and Winkel 2001, Jenni and Kéry 2003, Tøttrup et al. 2006a). Studies of changes in timing of migration have dealt with timing at the population level and in most cases we still lack the link to individual behaviour needed to improve our understanding of the changes (Knudsen et al. 2011, but see Tøttrup et al. 2012b).

Several studies have shown individuals to time migration consistently between years, in species ranging from swans and geese to raptors, shorebirds and songbirds. For example, bar-tailed godwits Limosa lapponica showed very high repeatability of spring departure $(r=0.83$; Battley 2006, $r=0.84$; Conklin and Battley 2011) as did adult marsh harriers Circus aeroginosus $(r=0.99$ in a small sample of 3 birds performing 9 departures; Vardanis et al. 2011). Reported spring arrivals have generally been slightly less repeatable, for example arrival in snow geese Chen caerulescens ( $r=0.42$; Bêty et al. 2004), black-tailed godwit Limosa limosa ( $r=0.18$; Gunnarsson et al. 2006) and even close to zero $(r=0.04$; Potti 1998) for breeding area arrival of pied flycatchers Ficedula hypoleuca. However, from repeatabilities alone one cannot directly conclude about absolute consistency because repeatability is a relative measure comparing the variation between and within individuals. Thus, with a given degree of absolute consistency in individual timing, repeatability will be high or low depending on if the variation between individuals in the population is high or low relative to the within-individual variation (Conklin et al. 2013). In this study we focus on relative rather than absolute consistency of individual timing as reflected by repeatability estimates.

More varied, species-dependent patterns could be expected in autumn because of the less clear-cut expectations regarding autumn departure which is being influenced by many additional factors, including for example individual initiation and effort of breeding, breeding failure, relaying attempts or additional clutches (Phillips et al. 2005, Becker and Zhang 2011). The across-season correlation 
(for example from autumn to spring; in contrast to sameseason) has been evaluated in Bewick's swans Cygnus columbianus where individuals arriving early to the winter grounds tended to depart late (Spearman's rank correlation, $r=-0.36$; Rees 1989). The author suggested that this could be caused by responses to photoperiod but also noted the possibility that the pattern could be influenced by birds breeding at different latitudes. The opposite pattern was found in bar-tailed godwits Limosa lapponica in which individuals arriving early to the breeding grounds also departed early and timing was primarily determined by breeding latitude (Conklin et al. 2010).

Though empirical evidence indicates a significant heritability of timing (Nussey et al. 2005), it is an open question to what degree these differences are driven by differences in genotype or phenotype (Gienapp et al. 2007, 2008). Thus, high repeatability of individual timing could be caused by high heritability of migration timing or be the result of individual history (for example, fit individuals tending to fare better and arriving earlier every year; Pulido and Berthold 2004). Alternatively, high repeatability could also result from large variation among individuals as would result from including populations with different phenologies. Nevertheless, the study of repeatability can at least be seen as a first step to understand the underlying selective forces associated with migration timing.

Here, we study how consistently individual birds time their migration across a suite of songbird species. Furthermore, we test how individual timing in spring correlates with timing in autumn. We investigate this for 15 songbird species commonly occurring in Denmark on migration estimating consistency repeatabilities (i.e. measurements can have different means in contrast to agreement repeatabilities with constant mean; Nakagawa and Schielzeth 2010) by correlating date of ringing with date of recaptures. We focus on this relatively restricted geographical area to minimise complications of the natural variation in migration phenology along a migration route. To investigate potential effects of variation in phenology among populations and migration strategies, we first compared patterns of repeatability using speciesand season-specific estimates. Secondly, we applied a more general framework using a standardised data set aiming at estimating the support for different seasonal groupings (investigating if there were important differences in the correlation of migratory timing depending on if the correlation was between two spring seasons, between two autumn seasons, from spring to autumn or from autumn to spring, or between combinations of these four seasonal groups) and migration strategies (long- and short-distance migration) as well as changes over time.

\section{Methods}

Our data set consisted of passerine migrant birds ringed during migration in Denmark 1899-2002 (Bønløkke et al. 2006) and recaptured $<10 \mathrm{~km}$ from the site of ringing (Supplementary material Appendix 2, Fig. A1). We excluded the relatively few dead recoveries due to the less precise date associated with these. This resulted in most recoveries from continuous ringing operations with wide temporal coverage during spring and/or autumn seasons, but the selection contained both birds on direct migration as well as birds arriving to or departing from breeding or winter grounds. In general, migrating songbirds do not show extended use of specific stopover sites, like many shorebirds do, and thus captures can be assumed to be representative of migration timing. A crucial assumption for this analysis is that recapture probabilities do not differ temporally among individuals. This could arise for example if some birds were targeted on winter grounds and others during migration or during parts of the migration period. Such patterns will certainly influence the results to some degree, but as most recaptures stem from continuous ringing operations with wide temporal coverage we expect no major effect on the results. In total, 15 species were included in the analyses: 10 long-distance migrants in which at least part of the population is wintering south of the Sahara and 5 shortdistance migrants in which no birds are believed to winter south of the Sahara.

Only ringings and recaptures from the migration season were included. This was defined month by month for each species (Appendix 1). In general, the whole migration season was included but for a few species with large temporal overlap between migration and breeding and targeted catching effort in the breeding season (mostly hole-nesting species such as pied flycatcher) we chose a shorter period to exclude individuals captured on the breeding grounds. By choosing ringing and recaptures from the migration season we also aimed to minimise the presence of year-round sedentary individuals in the datasets which could otherwise bias the results.

The repeatability of timing was estimated by correlating the date of ringing with the date of recapture for each individual using Pearson's $r$. With a balanced design and two measurements per group this is straightforward and the estimates similar to other methods (Nakagawa and Schielzeth 2010). Large scatter in individual consistency caused a large degree of randomness for small sample sizes. Thus, to account for uneven measurement accuracy resulting from uneven sample sizes and to ensure useful speciesspecific estimates, we only included species for which at least ten birds were 1) recaptured one or more years later in the same season (spring or autumn) as the one they were ringed (same-season recapture) or 2) recaptured later in a different migration season (i.e. spring to autumn or autumn to spring, whether successive or not; across-seasons recaptures). If more than one recapture of the same bird existed in one season (spring or autumn), we included the first recapture in a following season to make it comparable with the ringing occasion which would always be the first capture. Furthermore, this procedure ensured that each individual was only included once in each analysis which is required for a balanced design when calculating repeatabilites as correlation coefficients (Nakagawa and Schielzeth 2010). Most of the birds ringed were in their first (autumn) or second (spring) calendar year but exact information on age class distribution is lacking.

We estimated repeatabilities for each species individually for spring-spring, autumn-autumn, spring-autumn and autumn-spring. Data on ringing date in spring and recapture date in autumn and ringing in autumn and recapture in 
spring were combined to calculate the overall correlation coefficient across seasons for each species as shown in Appendix 1. We tested for differences between the seasonal groupings using a $t$-test. We calculated the averages of transformed individual correlation coefficients using using Fisher's $z$ tranformation (SAS 1990). Assuming normally distributed migration dates the transformed values are approximately normally distributed.

We aimed to control for the potential effect of different populations being involved in the data by specifically investigating the possibility that different geographic populations showed a tendency to migrate at different times in spring and/or autumn by testing whether the date of ringing correlated with the latitude or longitude of recaptures in the breeding (Supplementary material Appendix 2, Table A2) and wintering (Supplementary material Appendix 2, Table A3) seasons, respectively. We also investigated differences between sexes in one species (whitethroat Sylvia communis) in which sex is easily identifiable and in which sample sizes allowed critical analysis (spring-spring in both males and females and across-season in males).

We also investigated general associations across species and seasons in a standardised data set where, for each species and season, mean and standard deviation of captures and recaptures were adjusted to a mean of zero and unit standard deviation. For this data set, we tested the effects of seasonal grouping, migration distance, species as well as interactions between these by fitting general linear models in SAS 9.2 (Proc GLM, least squares fitting). The basic general linear model modelled recovery date as a function of ringing date. Because data had already been standardised, explanatory variables (factors) were not included but instead added as interactions terms with ringing date. Thus, we do not base inference on the factors occurring alone, which would violate a general assumption in ANCOVA. To investigate the effect of seasonal grouping, we ran models with three different seasonal groupings: 1) spring-spring, autumn-autumn, spring-autumn and autumn-spring (4SeasonGroups); 2) spring-spring, autumn-autumn and across-season (3SeasonGroups, where ringing-recovery data from autumn-spring and spring-autumn have been combined into one group); and 3) same- and across-season (2SeasonGroups, where ringing-recovery data from spring-spring and autumnautumn combined have been distinguished from data from autumn-spring and spring-autumn combined), and compared these with models without any seasonal grouping (i.e. all data combined irrespective of season of ringing and recapture). The support for the different models was evaluated using Akaike's information criterion, AIC.

We also used a standardised data set to investigate potential effects of changing migration phenology over time. In addition to ringing date, year was also standardised for each species and season to mean of zero and unit standard deviation. We fitted models with both year and ringing date as continous explanatory variables and estimated the slope of the relationship between ringing date and year and between ringing and recovery dates individually for each season and species. Overall, we found no effect of year and the analyses of the individually estimated slopes of the relationship between ringing and recovery dates taking year into account (Supplementary material Appendix 2, Table A4) yielded very similar results to the analysis based on simple correlations.

\section{Results}

Ringed individuals tended to time their migration similarly in different years (Table 1 and Appendix 1; for an example see Fig. 1). Overall, we found a positive correlation between date of captures in both spring and autumn (Table 1). In spring, the correlation coefficient, $r$, was positive for all 8 species with $>9$ recaptures (Appendix 1 ) and the average back-transformed correlation was 0.30 ( $\mathrm{p}<0.001$; t-test). In autumn, the correlation was positive for 5 out of 6 species (Appendix 1) and the overall correlation in autumn was 0.39 ( $\mathrm{p}<0.001 ; \mathrm{t}$-test).

We did not find such a clear pattern of timing across seasons. In most cases the correlation across seasons was negative (8 species with negative correlation coefficients and 4 species with positive correlations, considering species with $>9$ recoveries; Appendix 1) and the overall correlation coefficient of $r=-0.15$ was significantly negative (Table 1 ). This indicates a general pattern that early spring migrating individuals migrated late in autumn and late spring migrating individuals migrated early in autumn. We did not find evidence for differences between long- and short-distance migrants.

We did not find evidence for a pronounced effect of breeding latitude on the timing of spring migration (Fig. 2, Table 2). In no species was date of spring ringing significantly correlated with latitude or longitude of recapture (Supplementary material Appendix 2, Table A2) and the overall correlation with latitude was close to zero $(-0.01$; $\mathrm{p}>0.05$; t-test). Timing of autumn migration was more clearly correlated with breeding latitude (Fig. 2, Table 2). Autumn ringing date and breeding latitude and longitude of recapture were positively correlated in 4 out of 5 species (Supplementary material Appendix 2, Table A2) and the overall correlation with latitude was 0.35 ( $\mathrm{p}<0.05$; t-test) and for longitude $0.24(\mathrm{p}<0.05 ; \mathrm{t}$-test $)$. This means that there was a tendency for late autumn migrants to originate from relatively more northerly and easterly breeding populations.

Table 1. Average back-transformed correlation coefficients $(R)$ between same-season and across-seasons captures for a number of passerine species ringed in Denmark. Data on individual species are given in Appendix 1.

\begin{tabular}{|c|c|c|c|c|c|c|}
\hline \multirow[b]{2}{*}{ Dist } & \multicolumn{2}{|c|}{ Spring-spring } & \multicolumn{2}{|c|}{ Autumn-autumn } & \multicolumn{2}{|c|}{ Across-season } \\
\hline & $R$ & $\mathrm{n}$ & $R$ & $\mathrm{n}$ & $R$ & $n$ \\
\hline All & $0.300 * * *$ & 8 & $0.390 * * *$ & 6 & $-0.147 * *$ & 12 \\
\hline Short & 0.314 & 2 & 0.506 & 3 & -0.073 & 4 \\
\hline Long & $0.288^{* * *}$ & 6 & 0.239 & 3 & $-0.184^{*}$ & 8 \\
\hline
\end{tabular}

Spring-spring = ringed and recaptured in spring. Autumnautumn $=$ ringed and recaptured in autumn. Across-season $=$ ringed in spring and recaptured in autumn or vice-verca. Dist= migratory distance category of short- or long-distance migrants, respecively. $\mathrm{n}=$ number of species included. ${ }^{* \prime}=\mathrm{p}<0.05 ;{ }^{\prime * * \prime}=\mathrm{p}<0.05$; **** $=\mathrm{p}<0.001$. 

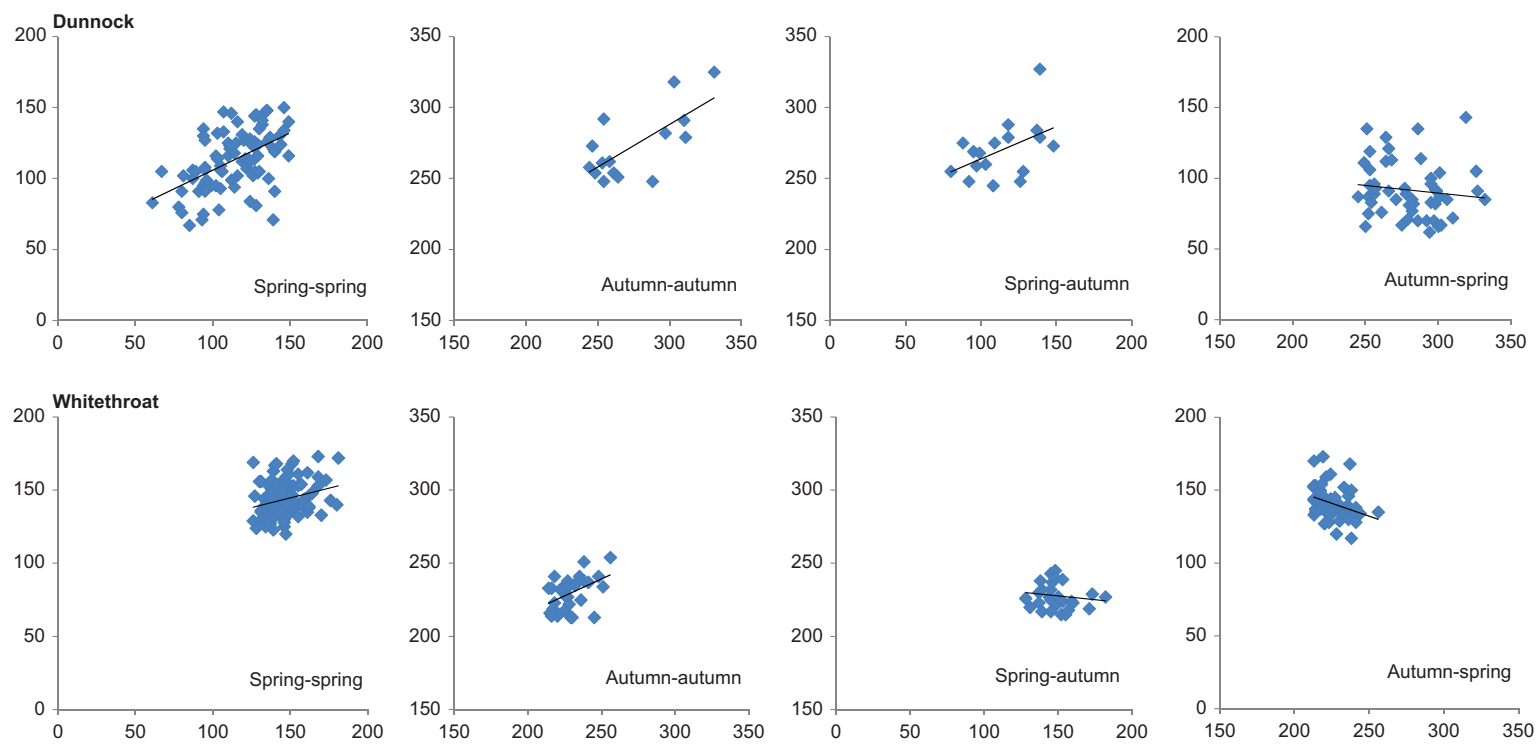

Figure 1. Timing of recapture date in relation to ringing date for recaptures from later seasons for the species with most recaptures; dunnocks Prunella modularis (upper row) and whitethroats Sylvia communis (lower row) ringed in Denmark, representing short- and long-distance migrants respectively. All dates are given as Julian days. The four panels show (from left to right): spring-spring, autumnautumn, spring-autumn and autumn-spring correlations.

Only for shorter-distance migrants were there more than 9 recaptures of any one species in winter (Supplementary material Appendix 2, Table A3). Similar to the results for breeding location, the correlations between geographical location of the winter positions and ringing date were stronger for birds ringed in autumn than in spring (Table 2). Autumn ringing dates and latitude and longitude of recapture were positively correlated in
5 (latitude) and 4 (longitude) out of 5 species, respectively (Supplementary material Appendix 2, Table A3), and the overall correlation with latitude was $0.41(\mathrm{p}<0.001 ; \mathrm{t}$-test) and for longitude $0.26(\mathrm{p}<0.05 ; \mathrm{t}$-test). This means that there was a tendency for late autumn migrants to travel to relatively more northerly and easterly winter quarters compared to individuals ringed earlier in autumn.
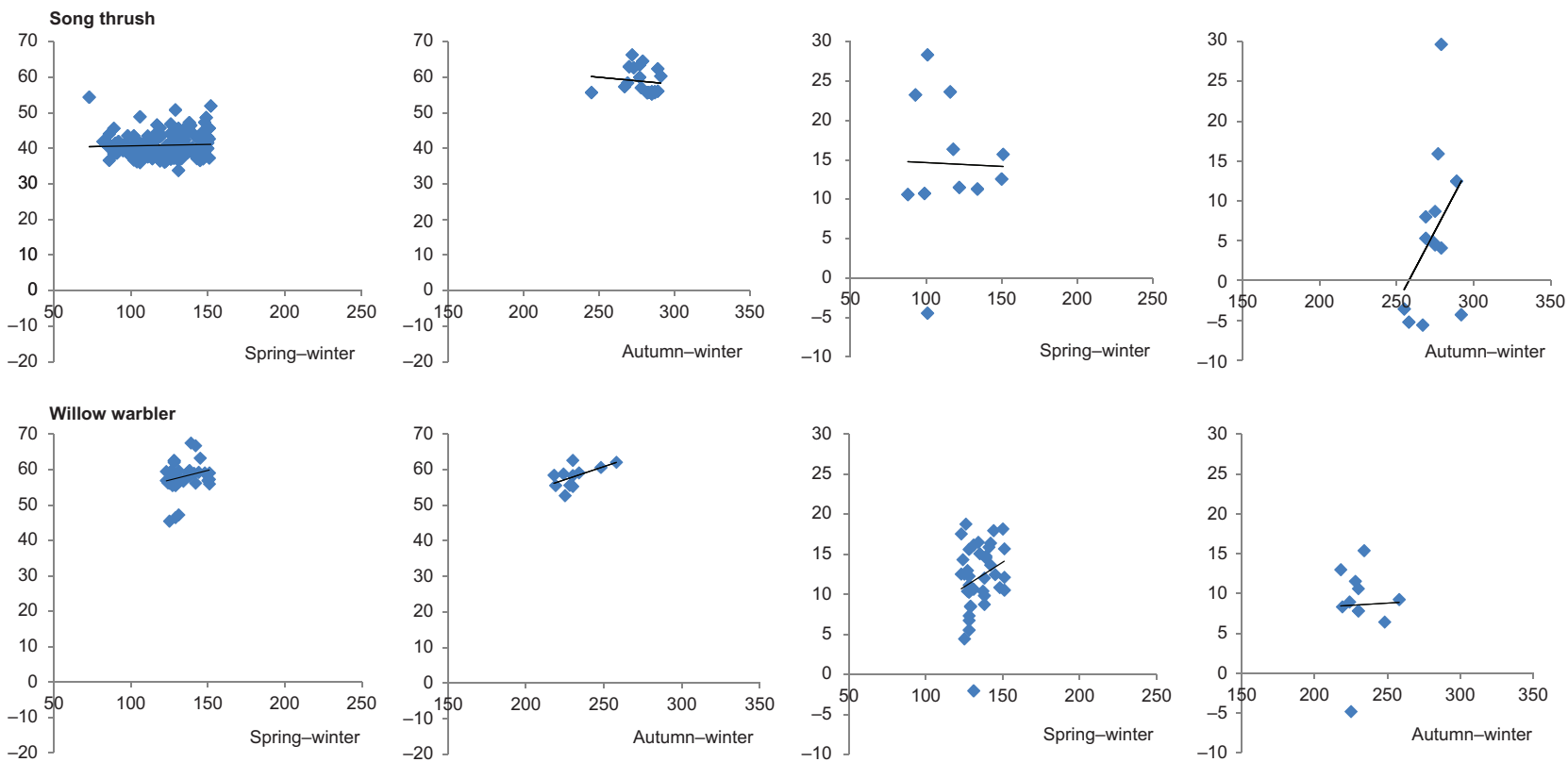

Figure 2. Top row: wintering latitude (degrees North, left two columns) and longitude (degrees East; right two columns) of recapture sites in relation to ringing date (Julian days) for recaptures from later winter seasons for a short-distance migrant, the song thrush Turdus philomelos, the species with most recaptures from the wintering season. Bottom row: breeding latitude (degrees North, left two columns) and longitude (degrees East; right two columns) of recapture sites in relation to ringing date (Julian days) for recaptures from later breeding seasons for a long-distance migrant, the willow warbler Phylloscopus trochilus, the species with most recaptures from the breeding season. 
Table 2. Average back-transformed correlation coefficients $(R)$ between date of ringing during migration and latitude $\left({ }^{\circ} \mathrm{N}\right) /$ longitude $\left({ }^{\circ} \mathrm{E}\right)$ of recovery during the breeding season or winter, respectively, for a number of passerine species ringed in Denmark. Data on individual species are given in Supplementary material Appendix 2, Table A2, A3.

\begin{tabular}{lcrrrr}
\hline & \multicolumn{2}{c}{ Latitude } & & \multicolumn{2}{c}{ Longitude } \\
\cline { 2 - 3 } \cline { 5 - 6 } & $R$ & $\mathrm{n}$ & & $R$ & $\mathrm{n}$ \\
\hline Spring-breeding & -0.001 & 11 & & 0.036 & 11 \\
Autumn-breeding & $0.350^{*}$ & 5 & & $0.236^{*}$ & 5 \\
Spring-wintering & -0.164 & 3 & & -0.068 & 3 \\
Autumn-wintering & $0.415^{* * *}$ & 5 & & $0.2624^{* *}$ & 5 \\
\hline
\end{tabular}

$*=p<0.05 ; * *=p<0.01 ; * * *=p<0.001$.

In whitethroat, there was a strong spring-spring repeatability in males $(r=0.352, \mathrm{n}=59, \mathrm{p}=0.006)$ whereas females showed no evidence of repeatability $(r=-0.130$, $\mathrm{n}=20, \mathrm{p}=0.59)$. Males did not show evidence of repeatability across seasons $(r=-0.040, \mathrm{n}=34, \mathrm{p}=0.82)$.

In the standardised data set with data from all seasons and species combined, we found strong support for differences in correlations between same-season and acrossseasons encounters (Table 3; $\Delta \mathrm{AIC}=1.99$ to a model with separate spring-spring, autumn-autumn and across-season estimates, $\Delta \mathrm{AIC}=3.96$ to a model with individual estimates for each same-season and across-seasons estimate, respectively; and $\triangle \mathrm{AIC}>50$ to a model without season). There was only some support for an effect of migration distance as the second best model $(\triangle \mathrm{AIC}=0.41)$ also included an effect of migration distance.
Table 3. Support for the general linear models of standardised recovery date as a function of ringing date, migration distance, species and different seasonal groupings based on Akaike's information criterion (AIC). Sample size is 1290 . The basic model \{.\} has recovery date as a function of ringing date. Because data had already been standardised, explanatory variables including the seasonal groupings (2SeasonGroups, 3SeasonGroups, and 4SeasonGroups), were added as interactions terms with ringing date. See text for further details.

\begin{tabular}{lrrrc}
\hline Model & $\mathrm{K}$ & \multicolumn{1}{c}{$\mathrm{AIC}$} & \multicolumn{1}{c}{$\Delta \mathrm{AIC}$} & $\mathrm{R}^{2}$ \\
\hline \{2SeasonGroups\} & 4 & -125.07 & 0.00 & 0.062 \\
\{MigrDist $\times$ 2SeasonGroups & 6 & -124.66 & 0.41 & 0.064 \\
\{3SeasonGroups\} & 5 & -123.08 & 1.99 & 0.062 \\
\{4SeasonGroups\} & 6 & -121.11 & 3.96 & 0.062 \\
\{Species $\times$ 2SeasonGroups\} & 31 & -100.44 & 9.84 & 0.083 \\
\{Species\} & 17 & -71.74 & 53.34 & 0.042 \\
\{.\} & 3 & -71.29 & 53.78 & 0.020 \\
\{MigrDist\} & 4 & -69.29 & 55.78 & 0.020 \\
\hline
\end{tabular}

$\mathrm{K}$ is number of parameters estimated to calculate AIC for each model (includes estimates of residual sums of squares and number of parameters).

The standardised model indicated a pattern of stronger correlation for same-season than across-season encounters. For this model with migration distance included as an interaction term, same-season encounters showed a steep positive slope $(\alpha=0.27, t=6.93, \mathrm{p}<0.0001$; and $\alpha=0.43, t=5.82, \mathrm{p}<0.0001$; for long- and short-distance migrants, respectively), much steeper than for across-seasons encounters $(\alpha=-0.12, \quad t=-2.16, \quad \mathrm{p}=0.03 ; \quad$ and $\alpha=-0.09, t=-1.36, \mathrm{p}=0.17$; for long- and shortdistance migrants, respectively; Fig. 3).

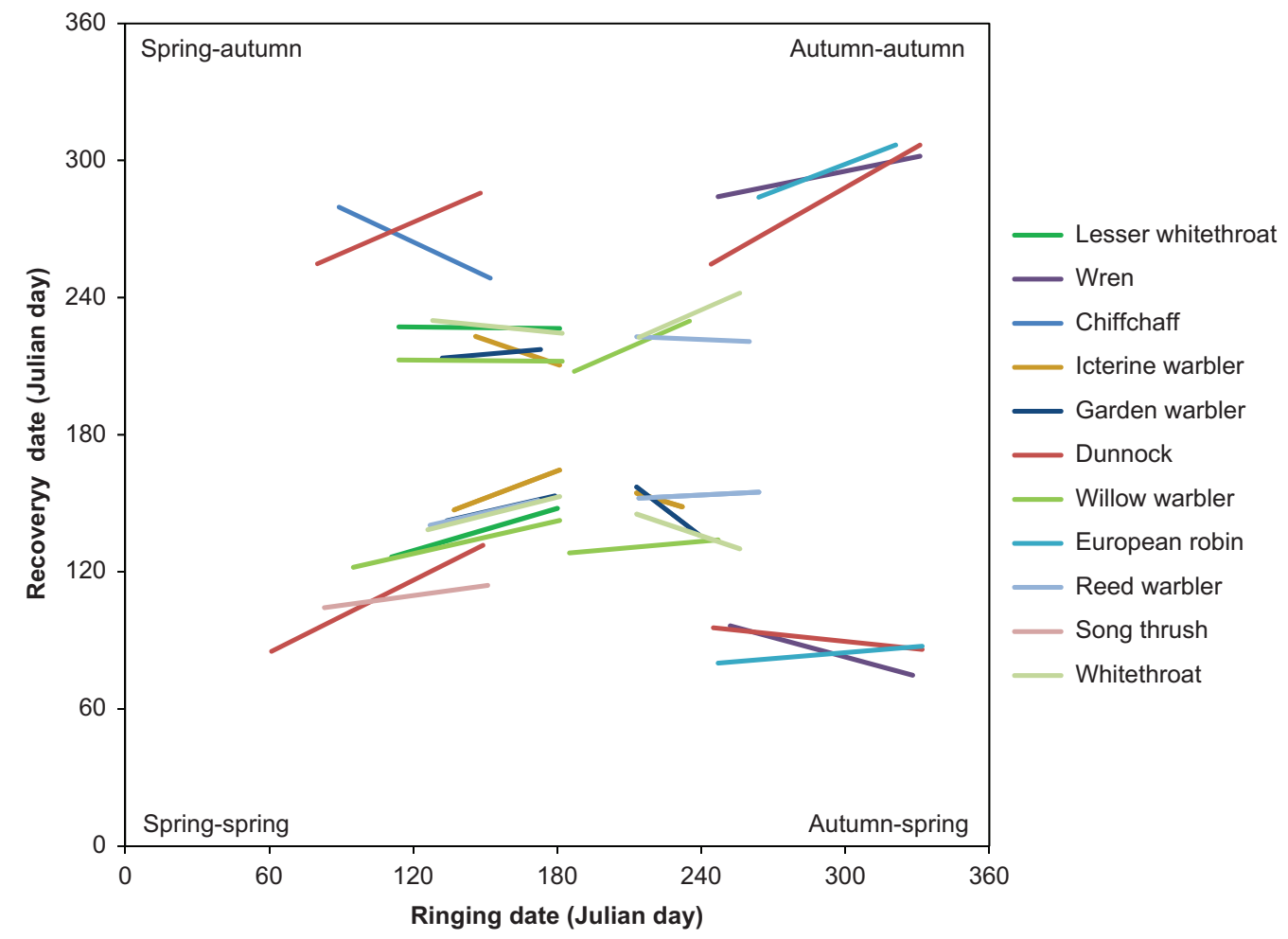

Figure 3. Correlation of individual migrations between years for species with 10 or more recaptures within a season. Linear regression lines estimated for each species separately. Timing of migration is shown in Julian days. Recovery date on the y-axis is plotted in relation to ringing date on the $\mathrm{x}$-axis. 


\section{Discussion}

The results showed a general pattern of positive correlation of migratory timing of individuals between different spring seasons as well as between different autumn seasons. The results rely heavily on the crucial assumption of homogeneity of seasonal recapture probabilities among individuals. Heterogeneity could result from temporally restricted, targeted ringing operations or from variations in effort during the seasons. Such biases cannot be ruled out but we tried to avoid them by restricting the time periods and mostly including data from continous ringing operations with wide temporal coverage.

The significant repeatability (ranges between 0.2 and 0.5 ) in within-season migratory timing among a large selection of common migratory passerine species in north Europe may have several contributory causes, e.g. 1) that individuals from different geographic breeding and/or wintering populations have consistent differences in the timing of migration through Denmark, 2) that individuals of different sex have consistent differences in migratory schedules and 3 ) that there exist consistent differences in migration timing between individuals of the same population and sex. The mostly weak and insignificant correlations between spring migratory timing and breeding latitude/longitude (Table 2) together with a distinct intrasex repeatability in migratory timing for male whitethroats (the only species allowing a critical assessement of intrasex repeatability) might indicate that the two first explanations are insufficient to fully account for our observed repeatabilities. Thus, we find it highly probable that the observed repeatabilities reflect to an important degree consistent differences in migratory timing between individuals of given populations and sex.

Migratory behaviour was the least repeatable behaviour in a meta-analysis of repeatability (Bell et al. 2009). Published studies on repeatability of migratory timing in terrestrial bird species show a large variation (several examples summarised in Table 4). Our estimates are within those previously reported for non-passerine taxa.

If the consistent differences between individuals reflect genetic differences, the repeatability may be regarded as an estimate of the upper limit of heritability of migratory timing (Boag and Noordwijk 1987; but see also Naya 2010). If this is so, the implication from our results would be that there exists significant genetic variation between individuals in migratory timing - variation that is presumably maintained by shifting selection favouring early or late

Table 4. Examples of studies reporting repeatability in migration timing of terrestrial bird species. $r_{i}=$ repeatability; $N_{\text {inds }}=$ no. individuals; $\mathrm{N}_{\text {rep }}=$ no. observations; sp. $=$ species; ${ }^{+}$and ${ }^{+t}$ indicate different study sites. Updated repeatability estimates, including recently accumulated data, are given by Vardanis et al. (unpubl.) for osprey (cf. Alerstam et al. 2006) and marsh harrier (cf. Vardanis et al. 2011).

\begin{tabular}{|c|c|c|c|c|}
\hline Stage & Taxa, sex/age & Repeatability (r) & $\mathrm{N}_{\text {inds }} / \mathrm{N}_{\text {rep }}$ & Reference \\
\hline \multirow[t]{3}{*}{ Autumn departure } & Ospreys Pandion haliaetus* & 0.17 & $8 / 22$ & Vardanis et al. (unpubl.) \\
\hline & Marsh harriers Circus aeruginosus* & 0.35 & $6 / 23$ & Vardanis et al. (unpubl.) \\
\hline & Bar-tailed godwits ${ }^{\dagger}$ Limosa lapponica & 0.47 & $6 / 12$ & Conklin et al. 2013 \\
\hline Autumn passage & Passerines (6 sp.) Passeriformes & 0.39 & $138 / 276$ & This study \\
\hline \multirow[t]{4}{*}{ Autumn arrival } & Bewick's swans Cygnus columbianus & 0.03 & $67 / 829$ & Rees 1989 \\
\hline & Ospreys Pandion haliaetus* & 0.04 & $7 / 20$ & Vardanis et al. (unpubl.) \\
\hline & Marsh harriers Circus aeruginosus* & 0.60 & $4 / 19$ & Vardanis et al. (unpubl.) \\
\hline & Bar-tailed godwits ${ }^{\dagger}$ Limosa lapponica & 0.66 & $44 / 88$ & Conklin et al. 2013 \\
\hline \multirow[t]{7}{*}{ Spring departure } & Bewick's swans Cygnus columbianus & 0.01 & $67 / 829$ & Rees 1989 \\
\hline & Ospreys Pandion haliaetus* & 0.38 & $4 / 13$ & Vardanis et al. (unpubl.) \\
\hline & Marsh harriers Circus aeruginosus* & 0.81 & $3 / 15$ & Vardanis et al. (unpubl.) \\
\hline & American redstarts Setophaga ruticilla & 0.38 & $74 / 195$ & Studds and Marra 2011 \\
\hline & Bar-tailed godwits ${ }^{++}$Limosa lapponica & 0.83 & $38 / 84$ & Battley 2006 \\
\hline & Bar-tailed godwits ${ }^{\dagger}$ Limosa lapponica & 0.84 & $45 / 135$ & Conklin and Battley 2011 \\
\hline & Bar-tailed godwits ${ }^{\dagger}$ Limosa lapponica & 0.82 & $49 / 98$ & Conklin et al. 2013 \\
\hline Spring passage & Passerines (8 sp.) Passeriformes & 0.3 & $570 / 1140$ & This study \\
\hline Spring migration duration & Greater snow geese ${ }^{\circ}$ Chen caerulescens & 0.37 & $20 / 41$ & Bêty et al. 2004 \\
\hline \multirow[t]{4}{*}{ Spring staging departure } & Greater snow geese ${ }^{\circ}$ Chen caerulescens & -0.02 & $36 / 76$ & Bêty et al. 2004 \\
\hline & Black-tailed godwits ${ }^{3}$ Limosa limosa & 0.3 & $20 / 56$ & Lourenço et al. 2011 \\
\hline & Black-tailed godwits + Limosa limosa & 0.42 & $31 / 84$ & Lourenço et al. 2012 \\
\hline & Bar-tailed godwits ${ }^{\dagger}$ Limosa lapponica & 0.92 & $8 / 16$ & Conklin et al. 2013 \\
\hline \multirow[t]{10}{*}{ Spring arrival } & Greater snow geese ${ }^{\circ}$ Chen caerulescens & 0.42 & $20 / 41$ & Bêty et al. 2004 \\
\hline & Marsh harriers Circus aeruginosus* & 0.63 & $3 / 15$ & Vardanis et al. (unpubl.) \\
\hline & Ospreys Pandion haliaetus* & 0.07 & $4 / 13$ & Vardanis et al. (unpubl.) \\
\hline & Black-tailed godwits Limosa limosa & 0.18 & $46 / 153$ & Gunnarsson et al. 2006 \\
\hline & Pied flycatchers ${ }^{\delta}$ Ficedula hypoleuca & 0.09 & $27 / 85$ & Potti 1998 \\
\hline & Barn swallows Hirundo rustica & 0.51 & $23 / 120$ & Møller 2001 \\
\hline & Dusky warblers ${ }^{2}$ hylloscopus fuscatus & 0.34 & $12 / 24$ & Forstmeier 2002 \\
\hline & Black-tailed godwits Limosa limosa & 0.18 & $70 / 228$ & Lourenço et al. 2011 \\
\hline & Black-tailed godwits Limosa limosa & 0.29 & $81 / 235$ & Lourenço et al. 2011 \\
\hline & Bar-tailed godwits ${ }^{\dagger}$ imosa lapponica & 0.91 & $8 / 16$ & Conklin et al. 2013 \\
\hline \multirow[t]{2}{*}{ Across seasons correlation } & Bewick's swans Cygnus columbianus & -0.36 & $67 / 134$ & Rees 1989 \\
\hline & Passerines (12 sp.) Passeriformes & -0.14 & $516 / 1032$ & This study \\
\hline
\end{tabular}

*For these two species, the time of migratory passage of $46^{\circ} \mathrm{N}$ has been used for departure from and arrival to breeding regions and $26^{\circ} \mathrm{N}$ has been used for departure from or arrival to wintering regions, respectively. 
migration in different years depending on changing environmental conditions between years.

We found generally weak and negative relationships between the individuals' migratory timing in different seasons, i.e. that individuals with an early passage in spring tended to be relatively late in autumn and vice versa. The weakly negative relationships were apparently stronger in long- than short-distance migrants (Table 1, Fig. 3) and were very similar for the comparison of spring (ringing) versus autumn (recapture) and autumn (ringing) versus spring (recapture), respectively, as clearly seen from Fig. 3. The best linear model to account for recapture date based on AIC included the interaction between ringing date and grouping in two seasonal categories (same season dates distinguished from across season dates). This confirms and underlines the fundamental difference in our data set between correlations in timing within seasons (from one spring season to another spring season or from one autumn to another autumn) and across seasons (from a spring to an autumn season or from an autumn to a spring season) as clearly seen from Fig. 3. The spring-spring and autumn-autumn correlation patterns are so similar (Fig. 3) that distinguishing between them does not improve the explanation of recovery date (Table 3). Likewise, springautumn and autumn-spring correlation patterns are highly similar (Fig. 3) and their separation gives no explanatory improvement of recovery date (Table 3). However, distinguishing between the two main within- and between season correlation patterns provides a strong explanatory improvement of recovery date (Table 3 ).

We consider the lack of correlation or the weakly negative correlation between recovery and ringing dates across seasons (autumn-spring or spring-autumn) as a most unexpected result, which is difficult to explain. However, absence of correlation between the timing of sequential migratory stages combined with significant between-year repeatability within them was also found in individual black-tailed godwits at specific locations along the return trip (Lourenço et al. 2011), suggesting that the relationships between different stages in the yearly cycle of a migrant can be more complex than a simple cascade of domino effects. These findings are in contrast to the evidence reported for ospreys and marsh harriers as revealed by satellite tracking during repeated journeys (Alerstam et al. 2006, Vardanis et al. 2011) and for red-backed shrikes tracked by geolocators during an annual cycle (Tøttrup et al. 2012a) that earlier individuals in postbreeding migration tended to be earlier also during the prebreeding migration, i.e. they tended to maintain their relative timing throughout the annual cycle. These studies focused on individuals from one single, limited breeding population. Individual bartailed godwits from across a large breeding range tracked by geolocators (Conklin et al. 2010) also tended to maintain relative timing. However, Bewick's swans arriving and departing from the winter grounds (Rees 1989) showed a negative repeatability similar to the ones reported here.

As suggested for the Bewick's swans, the tendency of a link between early spring migration and late autumn migration may be explained by population-specific differences in migratory schedules. This could be reflecting that more southerly breeding populations arrive to breed earlier in spring and have a longer breeding season. Despite that timing of migration was strongly correlated with individuals' breeding latitudes in Alaskan bar-tailed godwits (Conklin et al. 2010) the godwits did not show differences in length of individual breeding seasons according to latitude. Furthermore, this possibility was not strongly supported in the present study, where spring migratory timing was less consistently correlated with breeding latitude/longitude than expected (Table 2). In contrast, there was a clear correlation between autumn migration timing and geographical location of wintering as well as breeding sites. This pattern was driven by short-distance migrants because too few winter recoveries exist of long-distance migrants to calculate the correlations for these. If general, this means that individuals from more northerly breeding and wintering populations tend to migrate on average later in autumn than individuals from more southerly breeding and wintering populations.

One may speculate that early spring arrival at the breeding grounds may give the individuals access to the best breeding territories and promote a long breeding season, resulting in relatively late autumn migration. In common terns Sterna hirundo, early arriving individuals are generally the individuals in best condition and thus, also the ones that relay presumably causing delayed departure for these early individuals (Becker and Zhang 2011). However, it is difficult to see any similar reasons why early arrival at wintering grounds should lead to delayed spring migration. Another possibility is related to the control of the circannual rhythm of birds by photoperiod (Gwinner 1996). Perhaps there is a coupling in the regulation of migratory timing between seasons such that a photoperiod mechanism regulating early spring migration (at relatively short daylength) will also promote late autumn migration (also associated with relatively short daylength) as suggested by Rees (1989) to explain the tendency for late arriving Bewick's swans to depart early from the winter grounds. Further studies are needed to understand if the lack of correlation (or weakly negative correlation) between migration timing across seasons, as demonstrated for different songbirds in this study, is caused by differences in migration phenology between populations or if it reflects the fact that relative timing among individuals in a population often becomes broken up, or even slightly reversed, during the breeding and wintering phases of the annual cycle.

This study shows that there is a widespread and significant repeatability (in the range $r=0.2-0.5$ ) in migratory timing among both short- and long-distance migratory passerine species from one spring season to the next and from one autumn season to the next. The results also indicate that the individuals are not consistently early or late throughout the annual cycle. The fundamental question of individuality in timing of passerine migrants is largely unexplored especially at the multispecies level. Our study highlights the potential use of existing long-term ringing data sets and provides a methodological approach that can be of use in any other geographical area where these are available. 


\section{References}

Alerstam, T., Hake, M. and Kjellen, N. 2006. Temporal and spatial patterns of repeated migratory journeys by ospreys. - Anim. Behav. 71: 555-566.

Bairlein, F. and Winkel, W. 2001. Birds and climate chance. - In: Lozan, J. L., Grassl, H. and Hupfer, P. (eds), Climate of the 21 st century: changes and risks. Scientific Facts, GEO, Hamburg, pp. 278-282.

Battley, P. F. 2006. Consistent annual schedules in a migratory shorebird. - Biol. Lett. 2: 517-520.

Becker, P. H. and Zhang, H. 2011. Renesting of common terns Sterna hirundo in the life history perspective. - J. Ornithol. 152 (Suppl. 1): S213-S225.

Bell, A. M., Hankison, S. J. and Laskowski, K. L. 2009. The repeatability of behaviour: a meta-analysis. - Anim. Behav. 77: 771-783.

Bêty, J., Giroux, J. F. and Gauthier, G. 2004. Individual variation in timing of migration: causes and reproductive consequences in greater snow geese (Anser caerulescens atlanticus). - Behav. Ecol. Sociobiol. 57: 1-8.

Boag, P. T. and Noordwijk, A. J. van 1987. Quantitative genetics. - In: Cooke, F. and Buckley, P. A. (eds), Avian genetics. Academic Press, pp. 45-78.

Bønløkke, J., Madsen, J. J., Thorup, K., Pedersen, K. T., Bjerrum, M. and Rahbek, C. 2006. The Danish bird migration atlas. - Rhodos Press and Zoological Museum, Univ. of Copenhagen.

Conklin, J. R. and Battley, P. F. 2011. Impacts of wind upon repeatable individual migration schedules of New Zealand bar-tailed godwits. - Behav. Ecol. 22: 854-861.

Conklin, J. R., Battley, P. F., Potter, M. A. and Fox, J. W. 2010. Breeding latitude drives individual schedules in a transhemispheric migrant bird. - Nat. Commun. 1: 67.

Conklin, J. R., Battley, P. F. and Potter, M. A. 2013. Absolute consistency: individual versus population variation in annualcycle schedules of a long-distance migrant bird. - PLoS One 8: e 54535.

Dunn, P. 2004. Breeding dates and reproductive performance. - Adv. Ecol. Res. 35: 69-87.

Forstmeier, W. 2002. Benefits of early arrival at breeding grounds vary between males. - J. Anim. Ecol. 71: 1-9.

Gienapp, P., Leimu, R. and Merilä, J. 2007. Responses to climate change in avian migration time - microevolution versus phenotypic plasticity. - Clim. Res. 35: 25-35.

Gienapp, P., Teplitsky, C., Alho, J. S., Mills, J. A. and Merilä, J. 2008. Climate change and evolution: disentangling environmental and genetic responses. - Mol. Ecol. 17: 167-178.

Gordo, O. 2007. Why are bird migration dates shifting? A review of weather and climate effects on avian migratory phenology. - Clim. Res. 35: 37-58.

Gunnarsson, T. G., Gill, J. A., Atkinson, P. W., Gelinaud, G., Potts, P. M., Croger, R. E., Gudmundsson, G. A., Appleton, G. F. and Sutherland, W. J. 2006. Population-scale drivers of individual arrival times in migratory birds. - J. Anim. Ecol. 75: 1119-1127.

Gwinner, E. 1996. Circadian and circannual programmes in avian migration. - J. Exp. Biol. 199: 39-48.

Hüppop, O. and Hüppop, K. 2003. North Atlantic Oscillation and timing of the spring migration in birds. - Proc. R. Soc. B 270: 233-240.

Jenni, L. and Kéry, M. 2003. Timing of autumn bird migration under climate change: advances in long-distance migrants, delays in short-distance migrants. - Proc. R. Soc. B 270: 1467-1471.

Supplementary material (Appendix JAV-05871 at <www. oikosoffice.lu.se/appendix $>$ ). Appendix 2.
Knudsen, E., Lindén, A., Both, C., Jonzén, N., Pulido, F., Saino, N., Sutherland, W. J., Bach, L. A., Coppack, T., Ergon, T., Gienapp, P., Gill, J. A., Gordo, O., Hedenström, A., Lehikoinen, E., Marra, P. P., Møller, A. P., Nilsson, A. L. K., Péron, G., Ranta, E., Rubolini, D., Sparks, T. H., Spina, F., Studds, C. E., Sæther, S. A., Tryjanowski, S. A. and Stenseth, N. C. 2011. Challenging claims in the study of migratory birds and climate change. - Biol. Rev. 86: 928-946.

Lehikoinen, E., Sparks, T. H. and Zalakevicius, M. 2004. Arrival and departure dates. - Adv. Ecol. Res. 35: 1-31.

Lourenço, P., Kentie, R., Schroeder, J., Groen, N., Hooijmeijer, J. and Piersma, T. 2011. Repeatable timing of northward departure, arrival and breeding in black-tailed godwits Limosa l. limosa, but no domino effects. - J. Ornithol. 152: 1023-1032.

Moller, A. P. 2001. Heritability of arrival date in migratory bird. - Proc. R. Soc. B 268: 203-206.

Nakagawa, S. and Schielzeth, H. 2010. Repeatability for Gaussian and non-Gaussian data: a practical guide for biologists. - Biol. Rev. 85: 935-956.

Naya, D. 2010. Why may repeatability of highly flexible traits say little about their evolutionary potential? - Open Ecol. J. 3: 26-28.

Nussey, D. H., Postma, E., Gienapp, P. and Visser, M. E. 2005. Selection on heritable phenotypic plasticity in a wild bird population. - Science 310: 304-306.

Phillips, R. A., Silk, J. R. D., Croxall, J. P., Afanasyev, V. and Bennett, V. J. 2005. Summer distribution and migration of nonbreeding albatrosses: individual consistencies and implications for conservation. - Ecol. 86: 2386-2396.

Potti, J. 1998. Arrival time from spring migration in male pied flycatchers: individual consistency and familial resemblance. - Condor 100: 702-708.

Pulido, F. and Berthold, P. 2004. Microevolutionary response to climate change. - Adv. Ecol. Res. 35: 151-184.

Rees, E. C. 1989. Consistency in the timing of migration for individual Bewick's swans. - Anim. Behav. 38: 384-393.

SAS 1990. SAS/STAT user's guide. - SAS Inst., Cary, NC, USA.

Studds, C. E. and Marra, P. P. 2011. Rainfall-induced changes in food availability modify the spring departure programme of a migratory bird. - Proc. R. Soc. B 278: 1471-2954.

Thorup, K., Tøttrup, A. P. and Rahbek, C. 2007. Patterns of phenological changes in migratory birds. - Oecologia 151: 697-703.

Tøttrup, A. P., Thorup, K. and Rahbek, C. 2006a. Changes in timing of autumn migration in north European songbird populations. - Ardea 94: 527-536.

Tøttrup, A. P., Thorup, K. and Rahbek, C. 2006b. Patterns of change in timing of spring migration in north European songbird populations. - J. Avian Biol. 37: 84-92.

Tøttrup, A. P., Klaassen, R. H. G., Strandberg, R., Thorup, K., Kristensen, M. W., Jørgensen, P. S., Fox, J., Afanasyev, V., Rahbek, C. and Alerstam, T. 2012a. The annual cycle of a trans-equatorial Eurasian-African passerine migrant: different spatio-temporal strategies for autumn and spring migration. - Proc. R. Soc. B 279: 1008-1016.

Tøttrup, A. P., Klaassen, R. H. G., Kristensen, M. W., Strandberg, R., Vardanis, Y., Lindström, Å., Rahbek, C., Alerstam, T. and Thorup, K. 2012b. Drought in Africa caused delayed arrival of European songbirds. - Science 338: 1307.

Vardanis, Y., Klaassen, R. H. G., Strandberg, R. and Alerstam, T. 2011. Individuality in bird migration: routes and timing. - Biol. Lett. 7: 502-505. 
Appendix 1. Correlations between same-season and across-seasons captures for a number of passerine species ringed in Denmark.

\begin{tabular}{|c|c|c|c|c|c|c|}
\hline & Dist & Season & & Spring-spring & Autumn-autumn & Across-season \\
\hline \multirow[t]{2}{*}{ Pied flycatcher Ficedula hypoleuca } & Long & $4-5,8-10$ & $\mathrm{R}$ & 0.778 & & \\
\hline & & & $\mathrm{n}$ & 3 & 0 & 0 \\
\hline \multirow[t]{2}{*}{ Goldcrest Regulus regulus } & Short & $3-5,9-11$ & $\mathrm{R}$ & & 0.945 & 0.039 \\
\hline & & & $\mathrm{n}$ & 0 & 3 & 12 \\
\hline \multirow[t]{2}{*}{ Lesser whitethroat Sy/via curruca } & Long & $4-6,8-10$ & $\mathrm{R}$ & $0.318 * *$ & 0.152 & 0.018 \\
\hline & & & $\mathrm{n}$ & 89 & 4 & 22 \\
\hline \multirow[t]{2}{*}{ Wren Troglodytes troglodytes } & Short & $3-5,9-11$ & $\mathrm{R}$ & -0.011 & 0.399 & $-0.218^{*}$ \\
\hline & & & $\mathrm{n}$ & 9 & 13 & 95 \\
\hline \multirow[t]{2}{*}{ Chiffchaff Phylloscopus collybita } & Long & $3-5,8-10$ & $\mathrm{R}$ & -0.247 & 0.539 & -0.076 \\
\hline & & & $\mathrm{n}$ & 6 & 7 & 19 \\
\hline \multirow[t]{2}{*}{ Icterine warbler Hippolais icterina } & Long & $4-6,8-10$ & $\mathrm{R}$ & 0.327 & -0.596 & $-0.530 * *$ \\
\hline & & & $\mathrm{n}$ & 36 & 3 & 24 \\
\hline \multirow[t]{2}{*}{ Garden warbler Sy/via borin } & Long & $4-6,8-10$ & $\mathrm{R}$ & 0.235 & $0.728^{*}$ & -0.259 \\
\hline & & & $\mathrm{n}$ & 42 & 8 & 28 \\
\hline \multirow[t]{2}{*}{ Dunnock Prunella modularis } & Short & $3-5,9-11$ & $\mathrm{R}$ & $0.505^{* * *}$ & $0.701^{* *}$ & -0.082 \\
\hline & & & $\mathrm{n}$ & 91 & 15 & 67 \\
\hline \multirow[t]{2}{*}{ Willow warbler Phylloscopus trochilus } & Long & $4-6,7-10$ & $\mathrm{R}$ & $0.313^{* * *}$ & 0.308 & 0.029 \\
\hline & & & $\mathrm{n}$ & 121 & 24 & 78 \\
\hline \multirow[t]{2}{*}{ Blackcap Sylvia atricapilla } & Long & $4-6,8-10$ & $\mathrm{R}$ & -0.128 & & -0.397 \\
\hline & & & $\mathrm{n}$ & 6 & 0 & 11 \\
\hline \multirow[t]{2}{*}{ European robin Erithacus rubecula } & Short & $3-5,9-11$ & $\mathrm{R}$ & & 0.419 & -0.028 \\
\hline & & & $\mathrm{n}$ & 2 & 12 & 39 \\
\hline \multirow[t]{2}{*}{ Common redstart Phoenicurus phoenicurus } & Long & $4-6,7-10$ & $\mathrm{R}$ & 0.572 & & -0.671 \\
\hline & & & $\mathrm{n}$ & 8 & 0 & 4 \\
\hline \multirow[t]{2}{*}{ Reed warbler Acrocephalus scirpaceus } & Long & $4-6,8-10$ & $\mathrm{R}$ & 0.266 & -0.076 & 0.019 \\
\hline & & & $\mathrm{n}$ & 46 & 44 & 33 \\
\hline \multirow[t]{2}{*}{ Song thrush Turdus philomelos } & Short & $3-5,8-11$ & $\mathrm{R}$ & 0.144 & 0.277 & -0.167 \\
\hline & & & $\mathrm{n}$ & 26 & 5 & 5 \\
\hline \multirow[t]{2}{*}{ Whitethroat Sy/via communis } & Long & $4-6,8-10$ & $\mathrm{R}$ & $0.267 * *$ & $0.454^{*}$ & -0.201 \\
\hline & & & $\mathrm{n}$ & 119 & 30 & 88 \\
\hline
\end{tabular}

Spring-spring = ringed and recaptured in spring. Autumn-autumn = ringed and recaptured in autumn. Across-season = ringed in spring and recaptured in autumn or vice-verca. Dist $=$ migratory distance category. Season $=$ months included. $\mathrm{R}=$ correlation coefficient. $\mathrm{n}=$ sample size. 